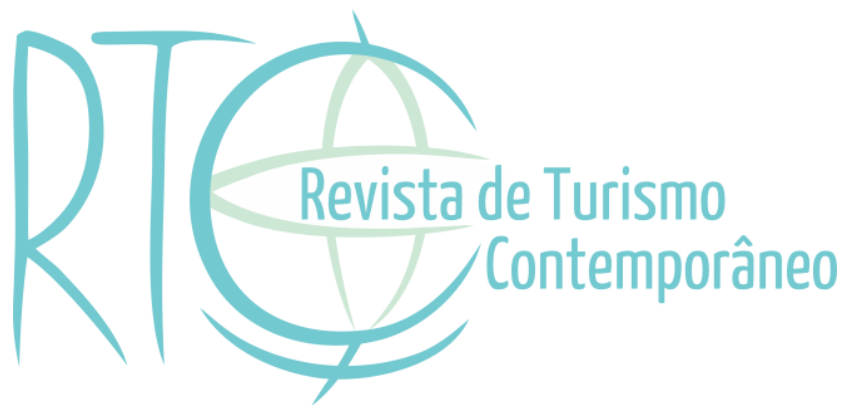

\title{
Planejamento do turismo através de políticas públicas: Análise SWOT dos planos de marketing de turismo no Brasil
}

\section{Tourism planning through public policies: swot analysis of tourism marketing plans in Brazil}

\section{Lucimari Acosta Pereira}

Professora de Ciências Humanas e da Informação da Universidade Federal do Rio Grande - FURG, Rio Grande/RS, Brasil

E-mail: lucimari.svp@gmail.com

\section{Antônio Carlos Benetti}

Discente do Programa de Pós Graduação - Mestrado em Turismo e Hotelaria da Universidade Do Vale do Itajaí - Univali, Itajaí/SC, Brasil

E-mail: manobenetti@gmail.com

\section{Angela Maria Carrión Carracedo Ozelame}

Professora Titular do Curso Técnico de Guia de Turismo e Eventos do Instituto Federal do Mato Grosso - IFMT/Octayde Jorge da Silva, Cuiabá/MT, Brasil

E-mail: angelacarrion.tur@gmail.com

Wilker Ricardo de Mendonça Nóbrega

Professor adjunto III do departamento de turismo da Universidade Federal do Rio Grande do Norte - UFRN, Natal/RN, Brasil

E-mail: wilkernobrega@yahoo.com.br 


\section{RESUMO}

As Políticas Públicas vêm sendo utilizadas expressivamente no âmbito mundial, como uma estratégia dos órgãos públicos, para o melhor planejamento administrativo global, estadual e local, reorganizando social, econômico, cultural e turisticamente o espaço planejado. No Brasil, o Ministério do Turismo é um dos atores públicos a empregar essa ferramenta no setor turístico com seus Planos de Marketing em sua Gestão. O presente trabalho de pesquisa tem como objetivo analisar através do método de análise SWOT as forças, as fraquezas, as oportunidades e as ameaças, onde envolve o monitoramento do ambiente externo e interno dos planos de marketing do Ministério do Turismo do Brasil nos documentos Planos de Marketing de Turismo do Brasil, onde analisou o Plano cores 2003, Plano Aquarela 200720010 e o Plano Aquarela 2020. A metodologia utilizada foi exploratória descritiva com abordagem qualitativa e o método da pesquisa foi o de análise documental e revisão bibliográfica em livros, artigos científicos e documentos online da Empresa Nacional de Turismo (EMBRATUR) e da página do Ministério do Turismo (MTUR). Buscando neste trabalho, através de uma análise das ações governamentais o entendimento da aplicação das Políticas Públicas no setor do Turismo.

Palavras-chave: Políticas Públicas. Planos de Marketing. Analise SWOT.

\section{ABSTRACT}

Public Policies have been used expressively in the global environment, as a strategy of public agencies, for the best local, state and global administrative planning, reorganizing socially, economically, culturally and touristically the planned space. In Brazil, the Ministry of Tourism is one of the public sectors to use this tool in the tourism sector with its marketing plans in its management. This research aims to analyze, through the SWOT analysis method, the forces, weaknesses, opportunities and threats, which involves the monitoring of the external and internal environment of the marketing plans of the Brazilian Ministry of Tourism in the Markting Plans of Tourism of Brasil, where it is analyzed the 2003 Colors Plan, Aquarela 2007-2010 Plan and the Aquarela 2020 Plan. The methodology used was an exploratory, descriptive study with a qualitative approach and the research method was the documentary analysis and bibliographic review in books, scientific articles and online documents of the National Tourism Company (EMBRATUR) and the webpage of the Ministry of Tourism (MTUR). Seeking in this work, through an analysis of the governmental actions the understanding of the application of the Public Policies in the Tourism sector.

Keywords: Public Policy. Marketing Plans. Analyze Swot. 


\section{INTRODUÇÃO}

O cenário atual do Brasil é de crescimento econômico e um dos setores que mais cresce é o turismo de acordo com a OMT (2001), neste sentido faz-se necessária a criação de políticas públicas que venham a afirmar e incentivar o crescimento do setor. A fim de fazer do turismo uma alternativa de atividade econômica, beneficiando de forma sustentável cidades e regiões, sendo que os desenvolvimentos do turismo a partir de políticas públicas geram oportunidades de cunho econômico, social e cultural criando oportunidades de modernização, nota-se então que há uma interdependência para que isso ocorra (Beni, 2006; Agüera \& López-Guzmán, 2015).

Cabe salientar que os atores em relação de interdependência que são envolvidos nas políticas públicas demostrando assim o quão importante às mesmas são para a sociedade em geral e seu sistema organizacional, são o "poder, status, legitimidade, conhecimento, informação e dinheiro; regras prevalecentes e mutáveis, que são fruto das interações e regulam o comportamento dos atores; e percepções que são imagens da realidade com base nas quais os atores interpretam e avaliam seu curso de ação e também o dos outros atores" (Fleury, 2008, p.78).

Considerando-se essa perspectiva de crescimento econômico e também social através do setor do turismo como aborda Beni (2006), Brasil (2010), o Ministério do Turismo criou planos de Marketing com a finalidade de crescimento do setor como um todo e com o intuito de melhorar a imagem do país reposicionando a mesma através de estratégias de marketing, para tanto a construção dos planos de marketing se tornam uma ferramenta de desenvolvimento (Brasil, 2010; Vignati, 2008 \& Chias, 2007).

Tendo em vista essas afirmativas de importância dos planos de marketing como ferramentas de política pública de desenvolvimento local, o presente artigo tem por objetivo geral analisar - as forças e as fraquezas dos planos de marketing brasileiros como um todo.

Quanto aos aspectos metodológicos, a pesquisa se caracteriza como exploratória descritiva com abordagem predominantemente qualitativa, onde para as incursões exploratórias foi utilizado o método de análise documental, para cumprir com objetivo geral da pesquisa foi utilizado o método de análise SWOT- que possui como dimensões 1) Forças (Strengths), 2) Fraquezas (Weaknesses), 3) Oportunidades (Opportunities) e 4) Ameaças (Threats).

Sendo assim o objetivo do trabalho com foco na análise das políticas públicas foi desenvolvido a partir da análise Swot, os resultados apontam os pontos fortes e os pontos 
fracos dos planos de marketing desenvolvidos em esfera governamental brasileira, e tendo em vista os resultados que são apontados o artigo contribui de forma não apenas acadêmica mas também gerencial com as instancias de governança.

\section{REFERENCIAL TEÓRICO}

\subsection{Políticas públicas e planejamento turístico}

Políticas públicas são um conjunto de ações que tem como objetivo construir o controle social sobre bens, serviços, e obras públicas, neste sentido são realizadas intervenções pelo poder público, instituições civis, entidades privadas ou grupos comunitários, elas devem atender a população e suas necessidades materiais e simbólicas, materializando normas jurídicas com intervenções diretas, amplas e pontuais (Gastal \& Moech, 2007).

A importância das políticas públicas advém de sua relação direta com os elementos de governança, que se ligam diretamente às discussões relacionadas ao desenvolvimento regional e do turismo (Nóbrega, 2012). “O conceito de política pública está associado a várias questões da sociedade, podendo-se citar a econômica, social, de segurança, ambiental e tecnológica, ou seja, a intervenção do Estado na sociedade através de estratégias de planejamento" (Nóbrega, 2012, p.93).

Vignati (2008), coloca que o turismo precisa de políticas próprias, que visem o crescimento em bases competitivas e sustentáveis, tendo em vista que o turismo tem complexidade no seu sistema econômico, assim como a diversidade dos agentes que influenciam no desenvolvimento e qualidade de um destino turístico.

No Brasil, a política de turismo evoluiu, com mudanças importantes e estas se caracterizam pela maturação do governo e empresariado no que tange a gestão de destinos, alguns exemplos sólidos são:

Quadro 1 -Criação e planejamento das políticas de Turismo

\begin{tabular}{|l|l|}
\hline Política Nacional de Turismo & $1996-1997$ \\
\hline Programa Nacional de Municipalização do Turismo & $2001-2003$ \\
\hline Ministério do Esporte e Turismo & 2003 \\
\hline Ministério do Turismo & 2003 \\
\hline Plano Nacional de Turismo & $2003-2007$ \\
\hline Programa de Regionalização do Turismo & 2004 \\
\hline Plano de Marketing Turístico Internacional & 2005 \\
\hline Plano de Marketing Turístico dirigido para o Mercado Doméstico & 2005 \\
\hline
\end{tabular}

Fonte: Vignati (2008). Adaptado pelos autores. 
Beni (2006), afirma que as formulações de políticas para o turismo norteiam o desenvolvimento turístico orientando as ações a serem executadas, neste sentido o autor ainda coloca que "a política de turismo e a direção ampla que orientará o desenvolvimento do setor, enquanto a estratégia constitui o meio para empregar os recursos disponíveis até a conquista dos objetivos" (Beni,2006, p. 313).

Nesse sentido a ação de planejamento turístico é uma importante ferramenta para organizações do trade turístico, é um processo inalterável e permanente de reflexão e análise para a escolha de alternativas que permitam alcançar determinados resultados a longo prazo, pode-se dizer que o planejamento é o alicerce para o desenvolvimento da atividade turística como um todo (Silva \& Silva, 2014).

Assim sendo, os planos de marketing turístico, constituem um instrumento norteador para as políticas públicas e iniciativa privada. O conteúdo construído a partir de um processo colaborativo entre mercado e as diversas esferas de governo tem o objetivo de contribuir para a implementação de melhores condições para o incremento do turismo interno no Brasil.

\subsection{Marketing no turismo e os planos de marketing}

No que tange a área de marketing e promoção para o turismo, se faz necessário ações incluindo pesquisas, desenvolvimento de produto e atividades de promoção que precisam ser realizadas durante o processo de comercialização a oferta turística (Acerenza, 2003).

O marketing de lugares segundo Gertner et al. (2006), abrange quatro atividades, desenvolvimento de um posicionamento e uma imagem forte e atraente, incentivos atraentes para possíveis consumidores e usuários, fornecimento de produtos e serviços de forma eficiente e promoção de valores e a imagem do local de maneira que os usuários se conscientizem da vantagem competitiva e o diferencial do destino.

O marketing turístico nos destinos vem assumindo um papel cada vez mais importante devido à falta de estabilidade nos mercados, há uma necessidade de demanda regular, onde o papel do marketing se torna cada dia mais importante no cenário turístico, dentro das organizações públicas e privadas onde a luta é para que se mantenham competitivos no mercado (Cooper et al., 2007).

Em conformidade com Dias e Cassar (2005), é necessária uma correta aplicação dos conceitos de marketing aliado ao crescimento do produto, a aplicação correta pode gerar aumento do fluxo de visitantes, se faz, portanto importante a aplicação de eficazes estratégias de marketing, um exemplo seria a preocupação com a satisfação do cliente, que quer levar pra 
casa um souvenir, para que este seja produzido é necessário que o destino se preocupe com a sensibilização dos artesãos locais, visando um trabalho conjunto e uma padronização da lembrança confeccionada para atender e satisfazer o cliente.

De acordo com Cooper et al (2007), no que tange o processo de desenvolvimento turístico o marketing tem um papel importante na melhoria de produtos e um papel menor em atender ao consumidor e a complexidade de seus processos de tomada de decisão.

No que se refere a ligação do marketing com o turismo, Churchil (2005) aborda que o marketing de lugar é uma tipologia que visa atrair o cliente para um lugar, para tanto são articuladas estratégias visando por exemplo atrair pessoas para um determinado destino, no seu período de férias.

Cooper et al (2007), afirmam que o Mix de Marketing tem relevância para o turismo, segundo o autor um Mix de Marketing bem sucedido é fundamental para que se garanta um mercado alvo bem definido de acordo com a segmentação. Kotler e Keller (2006), descrevem o Mix de Marketing como, "o conjunto de ferramentas de marketing que uma empresa usa para perseguir seus objetivos de marketing”. Os componentes são preço praça e promoção.

Sendo importante sua utilização também no que tange a formulação de Planos de Marketing que tem como intuito a promoção do pais visando no caso do Brasil reposicionamento de imagem.

De acordo com Churchil (2005), os planos de marketing oferecem inúmeros benefícios e ajuda aos membros de um departamento de marketing a identificar onde devem empregar seus esforços, para que possam tirar melhor proveito das oportunidades que o mercado oferece.

Na concepção de Chias (2007), um plano de marketing turístico tem como finalidade determinar as ofertas do produto que se fará no mercado, tendo como ponto de partida a realidade do produto turístico, isto é, aquilo que o turista quer consumir mesmo que seja gratuito, isso faz que o plano tenha que combinar estratégias de promoção a curto e longo prazo para que se tenha um aumento na captação de turistas.

Conforme Barreto (1991), o planejamento é um processo ativo e uma atividade dinâmica, não é estático, e possui muitos fatores concomitantes que necessitam ser analisados e coordenados para se alcançar um objetivo factível e satisfatório. É um processo que precisa ser constantemente repensado após o alcance dos objetivos traçados. Nessa perspectiva, planejamento é a organização sistemática de um conjunto de ideias e decisões, de forma integrada. 
Chias (2007, p. 35-36) aponta que um plano de desenvolvimento turístico, é composto por três fases no plano que consistem na análise, nas estratégias com definição de objetivos, ordenação dos recursos materiais e humanos, na determinação de métodos, tempo, indicação de localização espacial e no plano operacional. No Brasil têm-se os planos de Marketing que fazem parte do desenvolvimento e que são descritos abaixo.

O plano Aquarela Brasil é o plano de marketing turístico internacional do Brasil, os planos de marketing permitem avaliar as ações de divulgação do turismo e, na versão mais atualizada, propõem medidas reformuladas para alcançar melhores resultados. A primeira fase foi o Plano Cores do Brasil - Marketing Turístico Nacional foi divulgada em 2005, sendo o diagnóstico do marketing interno do turismo brasileiro, o documento apresenta informações sobre a situação e a oferta turística para o público interno, com análise dos produtos e do trade existente no País. Apresenta, ainda, a forma de promoção dos roteiros, uma pesquisa de satisfação com o público-alvo e um estudo sobre a segmentação do setor no Brasil. Após veio o Plano Aquarela 2003 - 2006 onde para de impulsionar o turismo foi necessário o país se propor a estudar e planejar ações, criando referências para todas as áreas de atuação (Brasil, 2015).

O Plano Aquarela 2007 - 2010 - Marketing Turístico Internacional do Brasil veio em seguida, e tornou-se um instrumento para as ações promocionais pela EMBRATUR - Instituto Brasileiro de Turismo - que permite um novo modelo de qualidade em promoção internacional. Após sua implantação, em 2003, o Plano Aquarela 2007/2010 avalia os resultados alcançados por meio das iniciativas da primeira edição do Plano e propõe nova versão com medidas reformuladas. O documento apresenta, ainda, dados estatísticos sobre o setor no Brasil e no mundo e elementos de mídia que divulgaram o País no exterior (Brasil, 2015).

O Plano Aquarela 2020 deu continuidade aos seis anos de planejamento do marketing turístico internacional, a EMBRATUR apresentou o Plano Aquarela 2020, e tem como foco principal traçar metas e objetivos para preparar o Brasil para os maiores eventos esportivos do mundo, um exemplo são os Jogos Olímpicos que aconteceram em 2016. Baseado em estudos e pesquisas, o plano contribui para ampliar a promoção do país como destino turístico, com estratégias e ações para aumentar o número de turistas estrangeiros e permanência dos mesmos visitando outros destinos, além de trabalhar a imagem do Brasil na mídia internacional (Brasil, 2015). 


\section{METOLDOLOGIA}

A pesquisa deste trabalho se apresenta de caráter qualitativo exploratório, onde forma empregados os métodos de análise documental e revisão da bibliografia utilizando-se de livros, artigos científicos e documentos on line disponíveis na página da Empresa Nacional de Turismo (EMBRATUR) e da página do MTUR - Ministério do Turismo (VEAL, 2001).

O universo da pesquisa foram os Planos de Marketing de turismo do Brasil onde se analisou desde o Plano Cores 2003, Plano Aquarela 2003-2006, Plano Aquarela 2007-20010 e Plano Aquarela 2020. A análise realizada foi a SWOT que tem como objetivo avaliar forças, fraquezas, oportunidades e ameaças e envolve monitoramento de ambiente externo e interno, no presente caso empregou-se a analise em documentos (Kotler, 2006).

Reafirmando os conceitos de Kotler, Força são as vantagens que uma empresa ou organização possui em relação aos seus concorrentes. Ou seja, as aptidões mais fortes. Já fraqueza é tudo que interfere ou que prejudica o andamento e desenvolvimento de uma empresa ou organização. Da mesma forma, oportunidade, são as forças e influências externas que impactam positivamente em uma empresa, como por exemplo mudança no cenário, investimentos planejados, mudança em políticas públicas de governo, etc. Por outro lado ameaça é tudo que pode influenciar negativamente o crescimento, funcionamento de uma empresa. Contudo, deve se ter um cuidado com a ameaça pois podem interferir no planejamento estratégico de uma empresa ou órgão público prejudicando os seus objetivos e resultados.

\section{ANÁLISE SWOT DOS PLANOS DE MARKETING}

Tendo como referência os resultados apresentados pelas políticas públicas utilizadas e considerando o atual estágio do turismo no Brasil, buscamos através da análise SWOT elencar os principais desafios e entraves ao desenvolvimento da atividade para os próximos anos, empregando os estudos realizados pela EMBRATUR.

Os temas mais relevantes foram agrupados por eixos temáticos, com o propósito de propiciar uma abordagem mais específica e articulada para facilitar a compreensão dos mesmos. Contudo, para a otimização dos resultados, é necessário salientar que os eixos embora se apresentem por temática, devem ser compreendidos de forma abrangente e complementar pois se relacionam entre si. 


\subsection{Planejamento e gestão}

A proposta de gestão descentralizada e compartilhada vem fomentando a consolidação de uma rede em prol do Turismo em todo o território nacional, envolvendo o poder público nas três esferas do governo, a iniciativa privada e o terceiro setor.

Quadro 2 - Análise para o eixo temático Planejamento e Gestão.

\begin{tabular}{|c|c|}
\hline \multicolumn{2}{|c|}{ Ambiente Externo } \\
\hline Oportunidades & Ameaças \\
\hline $\begin{array}{l}\text { - Desenvolvimento de instrumentos de } \\
\text { monitoramento da Política Nacional de } \\
\text { Turismo nos entes da federação; }\end{array}$ & $\begin{array}{l}\text { - Reduzida capacidade para gestão no nível } \\
\text { gerencial, tanto no âmbito governamental } \\
\text { quanto no setor privado; }\end{array}$ \\
\hline $\begin{array}{l}\text { - Ampliação do orçamento (verba de } \\
\text { programação) do MTur; }\end{array}$ & $\begin{array}{l}\text { Entraves ao desenvolvimento da atividade } \\
\text { turística entre países vizinhos. }\end{array}$ \\
\hline $\begin{array}{l}\text { - Fortalecimento da posição do MTur nos } \\
\text { megaeventos; }\end{array}$ & - Extinção do MTur; \\
\hline - Eleição de representante do turismo & - Redução do orçamento; \\
\hline brasileiro para direção executiva da OMT; & $\begin{array}{l}\text { - Falta de adesão dos entes da federação ao } \\
\text { PNT; }\end{array}$ \\
\hline \multicolumn{2}{|c|}{ Ambiente Interno } \\
\hline Forças & Fraquezas \\
\hline - Gestão descentralizada do turismo; & $\begin{array}{l}\text { - Pouca integração entre as diferentes } \\
\text { esferas de governo e entre os setores, } \\
\text { público e privado; }\end{array}$ \\
\hline $\begin{array}{l}\text { - Consolidação do Conselho Nacional de } \\
\text { Turismo como colegiado representativo; }\end{array}$ & $\begin{array}{l}\text { - Frágil participação das instâncias no } \\
\text { processo de gestão (Instâncias de } \\
\text { governanças macrorregionais, os Órgãos } \\
\text { Estaduais de Turismo, os Fóruns e } \\
\text { Conselhos Estaduais e Regionais }\end{array}$ \\
\hline $\begin{array}{l}\text { Apoio aos fóruns e conselhos estaduais e } \\
\text { regionais de turismo; } \\
\text { Aprovação da lei de turismo; }\end{array}$ & $\begin{array}{r}\text { Carência de maior articulação por afinidades e de } \\
\text { organização por categorias de atividade; }\end{array}$ \\
\hline
\end{tabular}

Fonte: Elaborado pelos autores, baseado na análise dos planos Cores e Aquarela, 2003 a 2006, 2007 a 2010 e 2020.

Para o sucesso destas iniciativas, é fundamental a articulação, de forma institucionalizada, dos órgãos governamentais e das representações da sociedade civil, no planejamento, coordenação e acompanhamento das ações a serem empreendidas, buscando potencializar os recursos demandados. Para tanto, considera-se que colegiados fortalecidos, Revista de Turismo Contemporâneo - RTC, Natal, v. 6, n. 1, p. 90-110, jan./jun. 2018. 
onde interagem estes diversos atores, constituem os ambientes propícios que devem permitir uma maior visibilidade, transparência e participação no planejamento das ações.

\subsection{Informação}

O desafio para obtenção de dados produzidos e organizados de forma sistemática e contínua não é um problema exclusivo do setor turístico, mas, especificamente, para esta atividade, são imprescindíveis informações que auxiliem na tomada das decisões. Por se tratar de uma atividade relativamente recente, este fato é agravado pela falta de referência conceitual. Além disso, trata-se de uma atividade econômica que não se define pela produção, mas pelo consumo, o que impõe grandes limitações na obtenção de dados pelos métodos estatísticos tradicionais. Avanços vêm sendo obtidos com relação à produção de estudos e pesquisas sobre o setor, o que tem propiciado maior efetividade nos processos de gestão.

Quadro 3 - Análise para o eixo temático Informação.

\begin{tabular}{|c|c|}
\hline \multicolumn{2}{|c|}{ Ambiente Externo } \\
\hline Oportunidades & Ameaças \\
\hline $\begin{array}{l}\text { - Padronização dos dados de demanda e } \\
\text { fluxos turísticos; }\end{array}$ & $\begin{array}{l}\text { - Descontinuidade metodológica dos } \\
\text { grandes centros de pesquisa; }\end{array}$ \\
\hline $\begin{array}{l}\text { - Redução de custos das tecnologias de } \\
\text { informação e comunicação; }\end{array}$ & $\begin{array}{l}\text { - Descontinuidade da produção de pesquisa } \\
\text { pelos grandes centros de pesquisa; }\end{array}$ \\
\hline - Unificação metodológica; & \\
\hline $\begin{array}{l}\text { - Produção de dados pelas instituições do } \\
\text { CNT; }\end{array}$ & \\
\hline \multicolumn{2}{|c|}{ Ambiente Interno } \\
\hline Forças & Fraquezas \\
\hline - $\quad$ Estudos e pesquisas; & - $\quad$ Gestão da informação; \\
\hline - $\quad$ Criação do CADASTUR; & $\begin{array}{l}\text { - Carência de dados censitários sobre os } \\
\text { serviços turísticos; }\end{array}$ \\
\hline - $\quad$ Portal do Ministério do Turismo; & $\begin{array}{l}\text { - Divulgação insuficiente dos dados } \\
\text { levantados; }\end{array}$ \\
\hline \multirow{2}{*}{$\begin{array}{l}\text { - Relacionamento permanente com o setor } \\
\text { empresarial através das sondagens } \\
\text { conjunturais. }\end{array}$} & $\begin{array}{l}\text { - Levantamento das demandas de } \\
\text { qualificação profissional; }\end{array}$ \\
\hline & $\begin{array}{l}\text { - No âmbito da qualificação profissional } \\
\text { para o setor, há grande carência de dados } \\
\text { que permitam sua mensuração; }\end{array}$ \\
\hline
\end{tabular}

Fonte: Elaborado pelos autores, baseado na análise dos planos Cores e Aquarela, 2003 a 2006, 2007 a 2010 e 2020. 
A dificuldade de obtenção de dados produzidos e organizados de forma sistemática e contínua não é um problema exclusivo do setor turístico, mas, especificamente, para esta atividade, são imprescindíveis informações que subsidiem as decisões. Por se tratar de uma atividade relativamente recente, este fato é agravado pela falta de referência conceitual. Além disso, trata-se de uma atividade econômica que não se define pela produção, mas pelo consumo, o que impõe grandes limitações na obtenção de dados pelos métodos estatísticos tradicionais. Grandes avanços vêm sendo obtidos com relação à produção de estudos e pesquisas sobre o setor, o que tem propiciado maior efetividade nos processos de gestão. Mas ainda existem lacunas para um conhecimento mais aprofundado da atividade e seus impactos.

A produção e a disseminação de informações baseadas em pesquisas contínuas e confiáveis proporcionam o surgimento de uma nova cultura, facilitando a profissionalização e otimizando a aplicação dos recursos públicos e privados. Para tanto, os estudos e pesquisas, que vêm sendo permanentemente elaborados, configuram importante avanço para a consolidação deste sistema. O processo de geração, sistematização e disseminação destas informações demanda constante aprimoramento e, portanto, este tema deve ser sempre priorizado.

\subsection{Estruturação da oferta turística}

O território brasileiro possui uma dimensão e uma diversidade tão grande que a estruturação e organização da oferta turística do país constituem um dos maiores desafios para a gestão e o desenvolvimento sustentável da atividade. A estruturação da oferta turística pode ser potencializada se considerada em sua dimensão regional, onde diversos municípios se integram e se complementam na prestação de serviços aos turistas, agregando valor aos territórios. Tendo este princípio como referência, o Ministério do Turismo criou e vem implementando o Programa de Regionalização do Turismo, pelo qual os municípios são incentivados a um trabalho conjunto de estruturação e promoção, no qual cada peculiaridade local pode ser contemplada, valorizada e integrada num mercado mais abrangente.

Quadro 4 - Análise para o eixo temático Estruturação da Oferta Turística

\begin{tabular}{|cc|c|}
\hline \multicolumn{2}{|c|}{ Oportunidades } & \multicolumn{2}{c|}{ Ameaças } \\
\hline • & Revisão do Programa de Regionalização do Turismo; & Descontinuidade das políticas e \\
\cline { 1 - 2 } programas do turismo; & \\
\hline $\begin{array}{l}\text { Estrutura de governança: as instâncias de governança } \\
\text { devem constituírem-se em espaços de articulação dos } \\
\text { atores sociais e de proposição, análise e monitoramento }\end{array}$ & \\
\hline
\end{tabular}




\begin{tabular}{|c|c|}
\hline $\begin{array}{l}\text { de políticas, planos e projetos na área do turismo } \\
\text { sustentável. }\end{array}$ & \\
\hline - $\quad$ Tendência de mercado por produtos regionais; & \\
\hline \multicolumn{2}{|l|}{ Ambiente Interno } \\
\hline Forças & Fraquezas \\
\hline - Programa de Regionalização do Turismo; & $\begin{array}{l}\text { - Governanças do Turismo } \\
\text { regional e municipal; }\end{array}$ \\
\hline - Ação ministerial junto aos 65 destinos indutores; & - $\quad$ Falta de cultura de \\
\hline $\begin{array}{l}\text { - Produtos e segmentos diversificados, possibilitando } \\
\text { expandir a oferta e comercialização; }\end{array}$ & $\begin{array}{l}\text { planejamento e de gestão } \\
\text { compartilhada }\end{array}$ \\
\hline - Política de Segmentação; & participativa; \\
\hline
\end{tabular}

Fonte: Elaborado pelos autores, baseado na análise dos planos Cores e Aquarela, 2003 a 2006, 2007 a 2010 e 2020.

Em função da diversidade de destinos turísticos do País, o Ministério optou por uma estratégia de priorização, que permitisse foco e potencialização dos recursos disponíveis. Para isso, foi definido o conceito de destino indutor, que é aquele capaz de induzir o desenvolvimento regional. A seleção dos destinos indutores considerou os 87 roteiros apresentados no $2^{\circ}$ Salão do Turismo em 2006, as avaliações e valorações do Plano de Marketing Turístico Internacional - Plano Aquarela e do Plano de Marketing Turístico Nacional - Plano Cores do Brasil, além de outros estudos e investigações sobre investimentos do governo federal e sobre as potencialidades desses destinos. Como resultado foram selecionados 65 destinos considerados indutores. Esses destinos, presentes em todas as Unidades Federadas, vêm recebendo investimentos técnicos e financeiros do MTur com o objetivo de aprimorá-los, e suas experiências e práticas exitosas devem ser multiplicadas (Embratur, 2014).

\subsection{Fomento}

O fomento à iniciativa privada é essencial para o desenvolvimento do Turismo, seja na disponibilização e acesso ao crédito, na captação de investimentos, na promoção de incentivos fiscais e na desoneração tributária como fator indutor para o aumento da competitividade. Diversas ações vêm sendo implementadas neste sentido, como a ampliação dos valores de financiamentos concedidos pelas instituições oficiais de crédito. Nesse sentido, são visíveis os avanços obtidos com melhorias nas condições operacionais das linhas de crédito, notadamente em termos de disponibilidade de recursos, prazo de pagamento, limite 
financiável e spread bancário (a diferença entre os juros que o banco cobra ao emprestar e a taxa que ele mesmo paga ao captar dinheiro). Destacam-se ainda as ações de promoção das oportunidades de negócios turísticos no País, no sentido de potencializar a captação de investimentos para o setor, tanto no mercado interno quanto no mercado internacional.

Quadro 5- Análise para o eixo temático Fomento

\begin{tabular}{|c|c|}
\hline \multicolumn{2}{|c|}{ Ambiente Externo } \\
\hline Oportunidades & Ameaças \\
\hline $\begin{array}{l}\text { - Reconhecimento do turismo como } \\
\text { uma atividade típica de exportação }\end{array}$ & - Informalidade empresarial. \\
\hline $\begin{array}{l}\text { - Ampliação das linhas de crédito e } \\
\text { melhorias nas condições para MPEs. }\end{array}$ & - Carga tributária do setor. \\
\hline \multicolumn{2}{|c|}{ Ambiente Interno } \\
\hline Forças & Fraquezas \\
\hline - $\quad$ Existência do FUNGETUR; & $\begin{array}{l}\text { - Dificuldades para acessar linhas de crédito } \\
\text { existentes; }\end{array}$ \\
\hline - $\quad$ PIB baixo do Turismo; & $\begin{array}{l}\text { - Funcionamento do sistema bancário, que se } \\
\text { pauta por um sistema de pontuação da } \\
\text { eficácia das suas agências que muitas vezes } \\
\text { não prioriza os programas oficiais de crédito } \\
\text { para o turismo; }\end{array}$ \\
\hline - $\quad$ Financiamento ao consumidor final; & \multirow{3}{*}{$\begin{array}{l}\text { - Precariedade de profissionalização dos } \\
\text { gestores privados tanto no que se refere à } \\
\text { apresentação dos projetos como na } \\
\text { regularização da documentação demandada } \\
\text { para financiamentos. }\end{array}$} \\
\hline $\begin{array}{l}\text { - Linha de crédito destinada ao setor } \\
\text { hoteleiro; }\end{array}$ & \\
\hline $\begin{array}{l}\text { - Melhoria das condições operacionais e } \\
\text { ampliação dos valores das linhas de } \\
\text { créditos concedidas pelas instituições } \\
\text { oficiais de crédito; }\end{array}$ & \\
\hline
\end{tabular}

Fonte: Elaborado pelos autores, baseado na análise dos planos Cores e Aquarela, 2003 a 2006, 2007 a 2010 e 2020.

Um indicador da posição cada vez mais significativa do Turismo na economia brasileira é o crescimento do volume de crédito que vem sendo destinado ao setor pelas instituições oficiais (Banco Nacional de Desenvolvimento Econômico e Social - BNDES, Banco do Brasil, Caixa Econômica Federal - CAIXA, Banco do Nordeste - BNB e Banco da Amazônia - Basa). Em 2009, foram concedidos financiamentos da ordem de R \$ 5,58 bilhões, o que representa um crescimento de $56 \%$ em relação aos financiamentos concedidos em 2008, e de $512 \%$ com relação a 2003, ano da criação do Ministério do Turismo. O valor acumulado de financiamentos concedidos ao longo destes sete anos chega a R \$ 18,38 bilhões. Além disso, vem se trabalhando na disponibilização de linhas de crédito para capital de giro das empresas do setor, em que merece menção a linha FAT Giro Setorial, que oferece capital de giro isolado para prestadores de serviços turísticos cadastrados no Ministério do Turismo, em condições bastante favorecidas (Embratur, 2014). 


\subsection{Qualificação}

Existe no País um conjunto de instituições que atua na área de qualificação profissional de uma maneira geral e na qualificação para o Turismo em particular. Entretanto, nem sempre está atuação se dá de forma integrada e articulada, resultando em sobreposição de esforços e desperdício de recursos. Além disso, são bastante frágeis ou inexistentes as análises, responsáveis por levantar, quantitativa e qualitativamente, as necessidades de ações de qualificação das instituições executoras é a ausência do estabelecimento de padrões mínimos para os cursos, que possam incorporar a demanda de empresários e trabalhadores, em políticas públicas voltadas ao desenvolvimento do Turismo.

Quadro 6 - Análise para o eixo temático Qualificação.

\begin{tabular}{|c|c|}
\hline \multicolumn{2}{|c|}{ Ambiente Externo } \\
\hline Oportunidades & Ameaças \\
\hline $\begin{array}{l}\text { - Conjunto de normas técnicas brasileiras para } \\
\text { empreendimentos e profissionais do turismo } \\
\text { publicadas pela ABNT, }\end{array}$ & $\begin{array}{l}\text { - Não foram identificadas ameaças neste } \\
\text { eixo temático. }\end{array}$ \\
\hline $\begin{array}{l}\text { - Concentrar as ações de qualificação dos } \\
\text { diversos agentes (Qualificação Profissional em } \\
\text { Turismo com foco nas ocupações relacionadas } \\
\text { ao atendimento e hospitalidade do turista - } \\
\text { Sistema S, MTur, etc.). }\end{array}$ & \\
\hline \multicolumn{2}{|c|}{ Ambiente Interno } \\
\hline Forças & Fraquezas \\
\hline $\begin{array}{l}\text { - No período de } 2003 \text { - } 2008 \text {, cerca de } 355.712 \\
\text { profissionais qualificados, nas regiões turísticas } \\
\text { priorizadas pelo Ministério; }\end{array}$ & - $\quad$ Sobreposição de esforços de qualificação; \\
\hline - $\quad$ Programa aventura segura; & $\begin{array}{l}\text { - Ausência de análises voltadas a levantar; } \\
\text { quantitativa e qualitativamente, as } \\
\text { necessidades de ações de qualificação } \\
\text { profissional e empresarial parra o turismo. }\end{array}$ \\
\hline $\begin{array}{l}\text { - Elaboração das normas de certificação para as } \\
\text { ocupações do turismo; }\end{array}$ & $\begin{array}{l}\text { - Ausência do estabelecimento de padrões } \\
\text { mínimos para os cursos, que possam } \\
\text { incorporar a demanda de empresários, } \\
\text { trabalhadores e políticas públicas voltadas } \\
\text { ao desenvolvimento do turismo; }\end{array}$ \\
\hline $\begin{array}{l}\text { - Desenvolvimento de metodologias específicas } \\
\text { de qualificação profissional e a experiência } \\
\text { obtida na aplicação destas; }\end{array}$ & $\begin{array}{l}\text { - Ausência de uma política objetiva e } \\
\text { unificada de qualificação dos recursos } \\
\text { humanos; }\end{array}$ \\
\hline $\begin{array}{l}\text { - Redes e estrutura de qualificação do Sistema S: } \\
\text { SENAC, SEBRAE; }\end{array}$ & $\begin{array}{l}\text { - Ausência de avaliação de resultados dos } \\
\text { programas de qualificação; }\end{array}$ \\
\hline
\end{tabular}

Fonte: Elaborado pelos autores, baseado na análise dos planos Cores e Aquarela, 2003 a 2006, 2007 a 2010 e 2020

De forma geral, o setor ainda necessita de uma política objetiva e unificada de qualificação dos recursos humanos, que se aproprie de toda a capacidade instalada para a oferta de qualificação profissional e empresarial, que se desenvolva em parceria com as entidades que atuam na área, bem como com as diversas categorias de empresas e 
profissionais prestadores de serviços turísticos, seja na educação formal, seja na área de formação técnica específica.

\subsection{Infraestrutura}

Um dos principais limitadores do crescimento da atividade turística no País, e da desejada expansão, diversificação, qualificação e desconcentração da oferta turística, refere-se à carência de infraestrutura. Esta carência se dá tanto no que se refere à infraestrutura básica, particularmente com relação à acessibilidade, à mobilidade urbana e ao saneamento, como também à infraestrutura turística, sobretudo nos itens sinalização turística e equipamentos receptivos, tais como: centros de recepção e informação ao turista, centros de convenções e feiras, terminais de passageiros e atracadores. A implementação e o funcionamento das infraestruturas constituem atribuição e competência governamental, nas três esferas de governo, por via direta ou por concessão a terceiros.

Quadro 7 - Análise para o eixo temático Infraestrutura.

\begin{tabular}{|c|c|}
\hline \multicolumn{2}{|c|}{ Ambiente Externo } \\
\hline Oportunidades & Ameaças \\
\hline - $\quad$ Criação do PAC; & - Falta de foco das emendas parlamentares; \\
\hline $\begin{array}{l}\text { - Direcionamento dos investimentos de } \\
\text { outros ministérios / emedas } \\
\text { parlamentares / PAC, considerando o } \\
\text { turismo como matriz de } \\
\text { desenvolvimento. }\end{array}$ & $\begin{array}{l}\text { - Ausência de planeamento na implantação } \\
\text { da regulamentação aeronáutica; }\end{array}$ \\
\hline - $\quad$ PAN (Plano Aeroviário Nacional); & $\begin{array}{l}\text { - Alocação de recursos governamentais para } \\
\text { infraestrutura básica e de apoio ao turismo, } \\
\text { ressente-se ainda de um trabalho mais } \\
\text { sistemático de articulação intersetorial para } \\
\text { a definição dos investimentos; }\end{array}$ \\
\hline \multicolumn{2}{|c|}{ Ambiente Interno } \\
\hline Forças & Fraquezas \\
\hline $\begin{array}{l}\text { - Recursos do Orçamento Geral da união } \\
\text { - OGU para infraestrutura turística; }\end{array}$ & $\begin{array}{l}\text { - Cultura / herança de gestão governamental } \\
\text { setorizada; }\end{array}$ \\
\hline $\begin{array}{l}\text { Programa de Desenvolvimento do } \\
\text { turismo Nacional - Prodetur; }\end{array}$ & $\begin{array}{l}\text { - Falta de levantamento dos equipamentos } \\
\text { turísticos (inventário dos equipamentos } \\
\text { turísticos); }\end{array}$ \\
\hline $\begin{array}{l}\text { Eficácia do MTur na execução do } \\
\text { orçamento destinado à infraestrutura; }\end{array}$ & 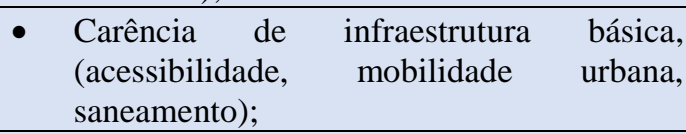 \\
\hline - $\quad$ Capacidade de articulação setorial; & - Carência de infraestrutura turística \\
\hline $\begin{array}{l}\text { Matriz de responsabilidades } \\
\text { mobilidade urbana e estádios; }\end{array}$ & $\begin{array}{l}\text { (sinalização turística, equipamentos } \\
\text { receptivos, centros de convenções e feiras, } \\
\text { terminais de passageiros e atracadores, } \\
\text { infraestrutura aeroportuária e aeronáutica). }\end{array}$ \\
\hline
\end{tabular}

Fonte: Elaborado pelos autores, baseado na análise dos planos Cores e Aquarela, 2003 a 2006, 2007 a 2010 e 2020. 
O compromisso com a realização da Copa do Mundo constituiu uma grande oportunidade para o fortalecimento da articulação intersetorial e da priorização dos investimentos governamentais, demandados pelo Turismo, nas três esferas da gestão pública. A constituição do Grupo Executivo da Copa e os compromissos assumidos na Matriz de Responsabilidade constituem um exercício de diálogo pelo qual o Turismo pôde ganhar cada vez maior reconhecimento como fator de desenvolvimento econômico e repercussão na alocação de recursos públicos e privados demandados para infraestrutura.

\subsection{Logística e transporte}

Uma das principais questões no âmbito deste tema diz respeito à vulnerabilidade do transporte aéreo que, entre outros problemas, apresenta uma limitação de oferta que pode vir a se constituir num entrave para a expansão do setor e para o desenvolvimento do Turismo nacional. Devem ser igualmente consideradas também as limitações relativas aos transportes terrestres (rodoviário e ferroviário) e aos transportes aquaviários (fluvial e marítimo). A viabilidade da proposta de inclusão de novas parcelas de consumidores no mercado turístico doméstico passa, necessariamente, pelo enfrentamento destas limitações. Neste sentido, discussões com órgãos correlatos têm sido realizadas e devem ter continuidade.

Quadro 8 - Análise para o eixo temático Logística e Transportes.

\begin{tabular}{|c|c|}
\hline \multicolumn{2}{|c|}{ Ambiente Externo } \\
\hline Oportunidades & Ameaças \\
\hline - Acordos de transporte internacional; & - Vulnerabilidade dos transportes; \\
\hline - Cruzeiro rodoviário; & $\begin{array}{l}\text { - Limitação de oferta aérea e rodoviária, } \\
\text { face à falta de infraestrutura; }\end{array}$ \\
\hline $\begin{array}{l}\text { Potencial de crescimento do setor } \\
\text { (crescimento da economia e do poder de } \\
\text { consumo das famílias); }\end{array}$ & $\begin{array}{l}\text { - Redução do número de assentos ofertados } \\
\text { pelas empresas aéreas brasileiras para o } \\
\text { mercado internacional. }\end{array}$ \\
\hline \multicolumn{2}{|c|}{ Ambiente Interno } \\
\hline Forças & Fraquezas \\
\hline $\begin{array}{l}\text { - Abertura e ampliação de novos portões } \\
\text { (aéreo) de entrada de turistas estrangeiros; }\end{array}$ & $\begin{array}{lllll}\text { - } & \begin{array}{l}\text { Legislação } \\
\text { rodoviário; }\end{array} & \text { restritiva } & \text { ao } & \text { turismo } \\
\end{array}$ \\
\hline $\begin{array}{l}\text { - Capacidade de atração de navios de } \\
\text { cruzeiro; }\end{array}$ & - Condições das vias; \\
\hline $\begin{array}{l}\text { - Turismo rodoviário, ferroviário, marítimo, } \\
\text { náutico, aéreo; }\end{array}$ & - $\quad$ Precariedade dos terminais; \\
\hline $\begin{array}{l}\text { - Interconectividade da malha aeroviária } \\
\text { doméstica; }\end{array}$ & $\begin{array}{l}\text { - Redução nas localidades atendidas pela } \\
\text { aviação aérea regional; }\end{array}$ \\
\hline \multirow[t]{4}{*}{$\begin{array}{l}\text { Estudos e documentos elaborados sobre o } \\
\text { setor de transportes; }\end{array}$} & $\begin{array}{l}\text { - Ausência de uma área técnica específica } \\
\text { na estrutura organizacional do Ministério } \\
\text { para tratar deste tema; }\end{array}$ \\
\hline & $\begin{array}{l}\text { - Falta de interconectividade da malha } \\
\text { aeroviária doméstica x internacional; }\end{array}$ \\
\hline & - $\quad$ Serviços aduaneiros; \\
\hline & - $\quad$ Excesso de movimentação nos principais \\
\hline
\end{tabular}


Fonte: Elaborado pelos autores, baseado na análise dos planos Cores e Aquarela, 2003 a 2006, 2007 a 2010 e 2020.

O desdobramento das questões relacionadas à Logística de Transportes envolve uma complexa rede de fatores a ser analisada, demandando dos órgãos de Turismo uma ação articulada com diversas instituições e entidades do poder público e da iniciativa privada. $\mathrm{O}$ que se constata é que existe um grande número de propostas traduzidas nos diversos planos e programas de diversos setores de governo em articulação com a iniciativa privada para os diversos modais de transporte. No entanto, este rico conjunto de informações e proposições não vem sendo gerenciada com a agilidade, a profundidade e a diversidade de expertises que a complexidade de fatores envolvidos demanda.

\subsection{Promoção e apoio à comercialização}

O produto turístico possui uma característica peculiar que orienta todos os itens relativos à promoção e apoio à comercialização: a decisão de compra do produto pelo consumidor final ocorre em um momento anterior a sua fruição.

Nesse sentido, a expansão da atividade no mercado interno e sua inserção de forma marcante no mercado internacional demanda uma ação estratégica e planejada de promoção, para que o produto possa, efetivamente, chegar ao público-consumidor. Esta ação exige articulação entre poder público e iniciativa privada, com o objetivo de apresentar o Brasil no mercado internacional como um produto competitivo em relação a outros destinos concorrentes, e no mercado interno em relação a outros produtos de consumo.

Quadro 9- Análise para o eixo temático Promoção e apoio à Comercialização.

\begin{tabular}{|c|c|}
\hline \multicolumn{2}{|c|}{ Ambiente Externo } \\
\hline Oportunidades & Ameaças \\
\hline $\begin{array}{l}\text { - Inclusão do turismo na cesta de consumo } \\
\text { do brasileiro; }\end{array}$ & - $\quad$ Taxa de câmbio; \\
\hline $\begin{array}{lll}\text { - } & \begin{array}{l}\text { Viabilidade em decorrência dos } \\
\text { megaeventos; }\end{array} & \\
\end{array}$ & $\begin{array}{l}\text { - Não construção de imagem única do país } \\
\text { para os megaeventos; }\end{array}$ \\
\hline $\begin{array}{l}\text { - Facilitação burocrática para visitação dos } \\
\text { países do Mercosul; }\end{array}$ & $\begin{array}{l}\text { - Prolongamento da crise financeira } \\
\text { internacional; }\end{array}$ \\
\hline - Abertura do mercado latino-americano; & - Aumento da demanda com impactos \\
\hline $\begin{array}{l}\text { - Aumento do mercado consumidor interno } \\
\text { (expansão da classe c ); }\end{array}$ & $\begin{array}{l}\text { negativos no meio ambiente e na } \\
\text { qualidade dos serviços. }\end{array}$ \\
\hline Ambien & erno \\
\hline Forças & Fraquezas \\
\hline - Valor do mercado interno; & $\begin{array}{l}\text { - Falta de sinergia entre os órgãos } \\
\text { governamentais que atuam no exterior; }\end{array}$ \\
\hline 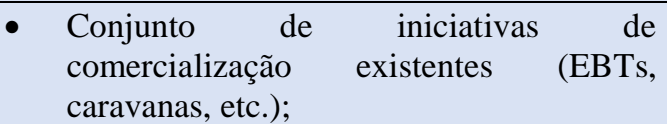 & $\begin{array}{l}\text { - Ordenamento jurídico para promoção no } \\
\text { exterior; }\end{array}$ \\
\hline - $\quad$ EMBRATUR; & $\begin{array}{l}\text { - Falta de indicadores de performance das } \\
\text { ações de promoção; }\end{array}$ \\
\hline
\end{tabular}




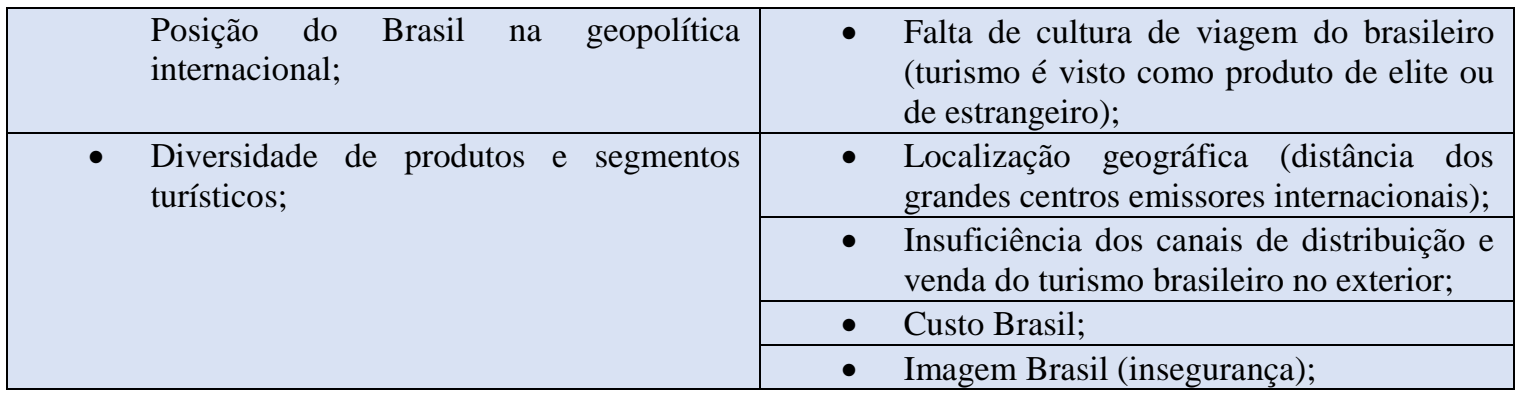

Fonte: Elaborado pelos autores, baseado na análise dos planos Cores e Aquarela, 2003 a 2006, 2007 a 2010 e 2020.

No que se refere à promoção interna, é necessário evoluir para ações mais focadas na demanda e nos perfis diferenciados dos consumidores. Há uma grande lacuna de informações e dados relativos aos hábitos de consumo dos turistas brasileiros, o que limita a eficiência dos resultados das ações de promoção. Este foco reforça a necessidade de avançar na produção e sistematização de informações e dados sobre a demanda turística, de modo a potencializar os resultados das ações de promoção.

Do lado da iniciativa privada, a diversificação de produtos buscando atrair para viagens domésticas os novos consumidores e também disputando os turistas brasileiros que viajam para o exterior, aliada a estratégias mais agressivas de vendas, tem permitido atender ao crescimento da demanda. De toda forma, é necessário que se trabalhe na melhora constante da qualidade e nos custos dos produtos e serviços oferecidos, que precisam ser competitivos num mercado mundial que disputa o crescente contingente de turistas brasileiros.

É importante reconhecer a importância das ações dos diversos atores que atuam no desenvolvimento do Turismo, voltados para a estruturação da oferta, mas também é vital para o crescimento do setor que considere a demanda, com o objetivo de elaborar e especificar novos investimentos, programas e ações. O desenvolvimento do mercado interno é fundamental para dar sustentabilidade ao turismo no País, principalmente frente à perspectiva de expansão do consumo nas diversas classes sociais. O turismo pode e deve ocupar um espaço cada vez maior nesta pauta de consumo dos brasileiros.

\section{CONSIDERAÇÕES FINAIS}

O presente trabalho evidenciou, através de uma análise das ações governamentais, que ao longo de sua história houveram alguns equívocos na atividade turística que são explicados segundo Beni (2006) pela ausência contínua de uma maior orientação que direcionasse objetivos, metas, prioridades e metodologias na elaboração de programas e projetos, tendo em vista que as políticas de turismo padeceram, durante muito tempo, com a 
falta de integração com outras políticas setoriais, e com as próprias políticas estaduais e municipais de turismo.

Em conformidade com Dias e Matos (2016), ao descentralizar o controle sobre as políticas públicas, o governo federal estimulou a inserção e participação de outros atores neste processo; tais como: sindicatos, a sociedade civil organizada, assim como algumas ONGs. Esse procedimento estimulou a participação da comunidade na tomada de decisões. Por conseguinte, podemos afirmar que a participação é uma parte essencial no desenvolvimento das sociedades humanas. Nesse contexto a participação das comunidades em assuntos que lhe dizem respeito é uma parte essencial do desenvolvimento

Alguns barreiras ainda existem, pois as políticas públicas de turismo ainda são um fato recente a perceber pela criação do Ministério próprio para a atividade turística que surgiu apenas em 2003 e. Dentre esses desafios encontrados para o desenvolvimento do turismo no Brasil, deve-se priorizar a melhoria dos produtos e serviços turísticos baseado na qualificação de equipe para elaboração e execução de bons projetos, além de investimentos financeiros em obras de recuperação de equipamentos turísticos e no fortalecimento de parcerias públicoprivadas. Da mesma forma, desenvolvendo planos de Marketing mais assertivos. O Programa de Regionalização sustentado na gestão compartilhada, participativa e descentralizada busca a valorização dos recursos e produtos turísticos e a ampliação dos destinos aos turistas, além da possibilidade de crescimento de cada município das regiões.

O destaque destas políticas públicas decorre também da articulação com os demais setores da sociedade, o que só se torna possível com o correto planejamento e formatação das políticas públicas.

Nesta acepção, como sugestão para futuras pesquisas, destaca-se a necessidade iminente de interpretar o turismo no contexto político-histórico nacional, dando segmento a essa respectiva evolução com a inserção dos resultados do Plano Nacional de Turismo 20132016 que consolida a Política Nacional de Turismo e apresenta as orientações estratégicas para o desenvolvimento da atividade no Brasil para os próximos anos e contribuindo para formatação de uma política cada vez mais consolidada.

Sugere-se novas análises comparando os planos de Marketing com os Nacionais de turismo analisando suas semelhanças e diferenças, este estudo não se esgota, mas encoraja-se outros pesquisadores a analisar os documentos abertos do MTUR e Embratur, a fim de relacionar o desenvolvimento real com o projetado. 


\section{REFERÊNCIAS}

Acerenza, M. (2003). Administração do Turismo . São Paulo: Edusc.

Aguera, F. O. \& López-Guzmán, T. (2015). Análisis Del Turismo Em República Dominicana: Un Análisis Foda. Observatório de Inovação do Turismo - Revista Acadêmica, 9(1), 1-27.

Barretto, M. (1991). Planejamento e organização em turismo. Campinas: Papirus.

Beni, M. C. (2006). Analise Estrututral do Turismo (11 ${ }^{\circ}$ ed.). São Paulo - SP: Aleph .

Brasil, M. d. ( 2004). Programa de Regionalização do Turismo - Roteiros do Brasil: diretrizes políticas. . Brasília.

Brasil, M. d. (2005). Plano Cores. Brasília .

Brasil, M. d. (2007-2010). Plano Aquarela 2007- 2010. Brasília: MTUR.

Brasil, M. d. (2010). Plano Aquarela 2020. Brasília : MTUR.

Brasil, M. d. (2013). Marketing de Destinos. Brasília: Assessoria de Comunicação Social e Marketing.

Chias, J. (2007). Turismo o Negócio da Felicidade: Desenvolvimento e marketing turístico de países, regiões e cidades. São Paulo : Senac.

Churchil, G. A. \& Peter, J. P. (2005). Marketing: Criando valor para os clientes (2 ed.). São Paulo: Saraiva,.

Cooper, C., Fletcher, J., Fyall, A., Gilbert, D. \& Wanhill, S. (2007). Turismo Principios e Praticas . Porto Alegre: Bookman.

Dencker, A. D. (2004). Planejamento e Gestão em Turismo e Hospitalidade. são Paulo: Thomsom.

Dias, R. \& Cassar, M. (2005). Fundamentos do Marketing Turístico. São Paulo : Pearson Pretince Hall .

Dias, R. \& Matos, F. (2012). Políticas Públicas: princípios, propósitos e processos. . São Paulo : Atlas.

Fleury, S. (2005). Redes de políticas: novos desafios para a gestão pública. Administração em Diálogo, 7, 77-89.

Gastal, S. \& Moech, M. (2007). Turismo, Políticas Públicas e Cidadania. São Paulo: Aleph.

Gertner, D. e. (2006). Marketing de Lugares. São Paulo: Pearson Education do Brasil Ltda.

Ignarra, L. R. (2003). Fundamentos do Turismo. (2 ed.). São Paulo: Thomson.

Kotler, P. \& Keller, K. L. (2006). Administraçao de Marketing. São Paulo: Pretince Hall. 
Nóbrega, W. R. (2012). Turismo E Políticas Públicas Na Amazônia Brasileira: Instâncias de governança e desenvolvimento nos municípios de Santarém e Belterra, oeste do estado do Pará (Vol. Tese De Doutorado). Belém: Universidade Federal Do Pará Núcleo De Altos Estudos Amazônicos Programa De Pós-Graduação Em Desenvolvimento Sustentável Do Trópico Úmido.

Ocke, M. A. \& Ikeda, A. A. (2013). Marketing de lugares: os recifes artificiais multifuncionais como proposta de atração turística. Revista Brasileira de Pesquisa em Turismo, 7(3), 496-512.

OMT, O. M. (2001). Introdução ao Turismo. São Paulo : Rocca.

Ruschmann, D. (1997). Turismo e Planejamento Sustentável: A proteção do meio ambiente. Campina/ São Paulo: Papirus.

Ruschmann, D. (São Paulo: Senac.). Turismo. Como aprender, como ensinar. Em M. Ansarah, Planejamento Turístico . São Paulo : Senac .

Silva, N. P. \& Silva, M. C. (2014). A importância do planejamento para o desenvolvimento do turismo sustentável no parque estadual do Guartelá - Paraná. , Balneário Camboriú-sc. Revista Turismo: Visão e Ação, 16(1), 167-184.

Veal, A. J. (2011). Metodologia de Pesquisa em Lazer e Turismo. São Paulo : Aleph .

Vignati, F. (2008). Gestão de destinos turísticos: como atrair pessoas para pólos, cidades e países. Rio de Janeiro: Senac. 